\title{
A Drawing Formalistic Aspects in School and Higher Learning Institutions
}

\author{
Marzuki Ibrahim, Hartini M Razali, Mazni Omar, Siti Fairuz Md Hashim, M Iqbal Badaruddin
}

\begin{abstract}
This research aims to identify formalistic aspects (design elements and principals) generally incorporated in school curriculum and the Faculty of Art \& Design curriculum in creating drawings. Formalistic aspects present in drawings will be contrasted against each other via a special test conducted to selected respondents of two different phases - prior and after university enrollment, which involved of 105 respondents. They were Sijil Pelajaran Malaysia (SPM) candidates that have undergone interview test prior to the Faculty of Art \& Design of Universiti Teknologi MARA (UiTM) Kelantan Branch September intake. During the second phase which was done after university enrollment, the same respondents were recruited to participate in the evaluation of their drawing skill. Currently, all respondents are at their second (02) semester in four programs offered at UiTM. Based on the analysis done to drawings created in the First Phase (before) and the Second Phase (after) university enrollment, several discoveries were made pertaining to the incorporation of formalistic aspects in drawing creation. From the results, several suggestions were presented. It is hoped that this work will lead to the improvement of the current high school curriculum in general and the curriculum of the Faculty of Art \& Design, in particular, in order to ensure that art is elevated to a higher level in the face of future challenges.

Keywords: Art and Design, Formalistic, Drawing, UiTM
\end{abstract}

\section{INTRODUCTION}

$\mathrm{V}$ isual Art Education is a compulsory subject in lower secondary school and an elective in upper secondary school. Visual Art Education Curriculum cover subjects linked to fine art, visual communication, design and traditional craft. Students have been taught theories and practical aspects of design, such as drawing, printing, graphic design, multimedia, environmental design, interior design, batik and much more. Visual Art Education strives to nurture a Malaysian generation that is art culture savvy. Apart from having a creative mind, the capacity of a student to make a drawing in Visual Art Education is essential. According to Ching dan Juroszek (2010), a drawing is "A process or Technique that depicts something like scenery objects or ideas through the production of lines upon a surface"

Looking back on history, drawing can be traced to prehistoric times when the discovery of drawings on the cave

Revised Manuscript Received on January 03, 2020.

* Correspondence Author

Marzuki Ibrahim*, Faculty of Innovative Design and Technology, UniSZA, Terengganu, Malaysia. Email: marzukiibrahim@unisza.edu.my

Hartini M Razali, Faculty of Art \& Design, UiTM Machang Branch, Kelantan, Malaysia. Email: hartini@uitm.edu.my

Mazni Omar, Faculty of Art \& Design, UiTM Machang Branch, Kelantan, Malaysia. Email: mazni867@uitm.edu.my

(c) The Authors. Published by Blue Eyes Intelligence Engineering and Sciences Publication (BEIESP). This is an open access article under the CC BY-NC-ND license (http://creativecommons.org/licenses/by-nc-nd/4.0/) walls included sketches of hunted animals in Altamira, Spain and Lascaux, France. The early drawings can be seen on the walls of the Pyramids of Egypt until the Renaissance. In addition to geographical and cultural factors, drawing will change according to civilisation and time. A variety of media, approaches, theories and drawing productions have been created in the $21^{\text {st }}$ century. However, essentially a drawing can be identified as the effect or mark that occurs on a surface. There are two distinct categories of drawing skills, which are students who are naturally good at drawing, and students who are good at drawing by formal or informal training.

At UiTM, basic painting courses are taught at levels 01 and 02 , including technical and media use. Students are also taught how to manipulate the main drawing elements, which are line, comparison rate, tone, space and shape. Understanding these formalistic aspects (elements and principles) is essential in the search for the identification, understanding and production of works of art. Formalistic aspects were also the key points to be asserted when drawing. 'Elements' consisted of lines, appearances, threads, shapes and values. Meanwhile, 'Principle' is composed of comparison rate, balance, repetition, rhythm, diversity, pattern, contra, unity, harmony and space. In this study, the researcher employed five formalistic aspects, namely line, comparison rate, tone, space and shape. This selection is made since these aspects are the ones generally used in the production of a drawing. The purpose of this limitation is to establish a research focus while also offering a more detailed analysis of the selected formalistic aspects.

\section{PROBLEM STATEMENTS}

Art education is one of the subjects that is gaining attention and is starting to attract a lot of student interest in exploring it. This field has proved to be a great success for many art students, both nationally and internationally. Art education has become a must for students to equip themselves in order to ensure the nation's capability in producing human capital with first class mentality.

Art education is closely linked to creativity. In addition, Michael (1982) describes that creativity is connected to a set of guidelines or standards that must be followed. Among other things, creativity is capable of producing or creating something new, different and unique, through the processes of thought-provoking, high motivation and the state of always having an open mind.

Published By: 
It is also characterized by unexpected results, encouragement to develop and enhance one's own ideas, differences, uniqueness, individuality and originality. There will be a cycle of creative thinking in the process of creativity, as well as an improvement in the importance placed to the process as opposed to the outcome. The strength of knowledge and skills coupled with self-exploration leads to the ability to critique by analyzing concepts and topics that are exploited and learned. More creativity is obtained by exploring the phases of creative development such as suggestion making, re-use, adaptation, alteration, magnification, rearrangement, removal, listing and other dimensions (analogy).

This research focuses on students who take Visual Arts Education as one of the subjects in school and are also interested in pursuing this this field at the university level. Therefore, this field requires a proper understanding of the basics of art and the implementation of certain formalistic aspects in the creation of quality work, in order to refute the thought of some who regards drawing as a lackadaisical activity and simply to draw without the need of in-depth learning.

That said, the researcher thus was compelled to take the initiative to embark on this research. The main aim of the research is to look at the effectiveness of school-based learning compared to after university entrance. This research will apply the formalistic aspects of line, tone, comparison rate, space and shape that are essential to the creation of a drawing.

Formalistic aspects are also central to the education of students at both high school and university levels. This study involved 216 students in semester 02 as respondents who had undergone OBE (outcome-based education) teaching. The research process was carried out by evaluating the assessment of drawings created during the recruitment interview at the Faculty of Art \& Design. It used the same setting that is to be evaluated and analyzed in order to obtain the results of formalistic aspects application observed before and after entering university (Art \& Design Faculty, UiTM).

\section{RESEARCH OBJECTIVES}

The objectives of this research are:

1. To identify the formalistic aspects generally applied in the school curriculum compared to those practiced at the university in the drawing of their students.

2. To measure the level of drawing production through drawing tests done before and after entering university.

3. To suggest viable improvements in school curriculum and university-level curriculum.

\section{METHODOLOGY}

\section{A. Experimental Design}

Fig. 1. SPM candidates who attend interviews and completing drawing tests for university admission (UiTM)

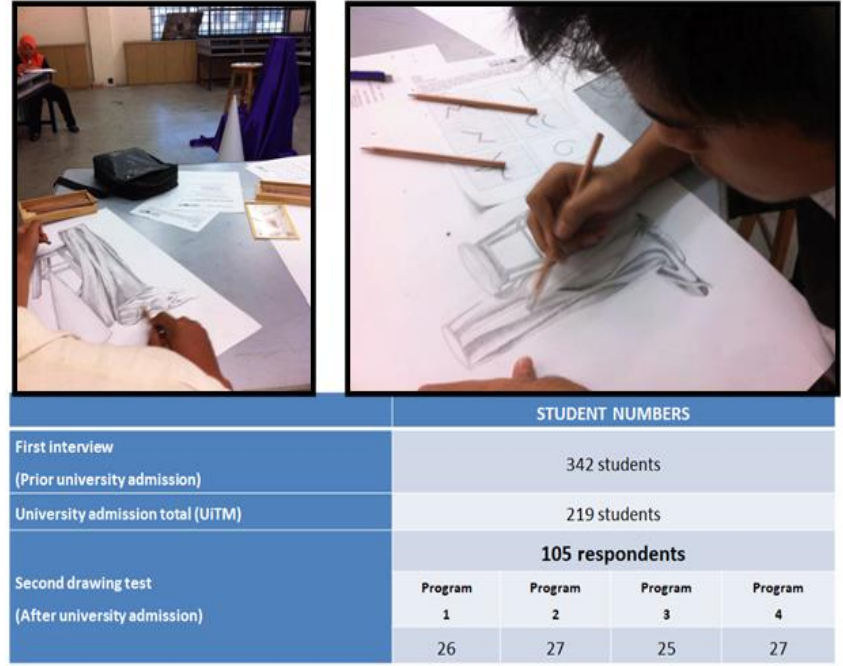

Diagram 1.

This research was initiated during the interview session and drawing test held for SPM leaver candidates for UiTM enrollment. A total of 342 students attended the interview session. The selection involved only a total of 105 respondents, that is those who succeeded the interview and was accepted into UiTM. All 105 respondents came from four UiTM Departments as depicted in diagram 1. above.

The second evaluation done after two semesters of formal education at the university. The students were evaluated based on the growth and application level of formalistic aspects learned during the first and second semester of their respective departments. The second evaluation was carried out exactly like the first. In this second assessment, students were reassembled and instructed to draw a predefined setting. The second evaluation employed element and principal usage rubic formulated by the researcher.

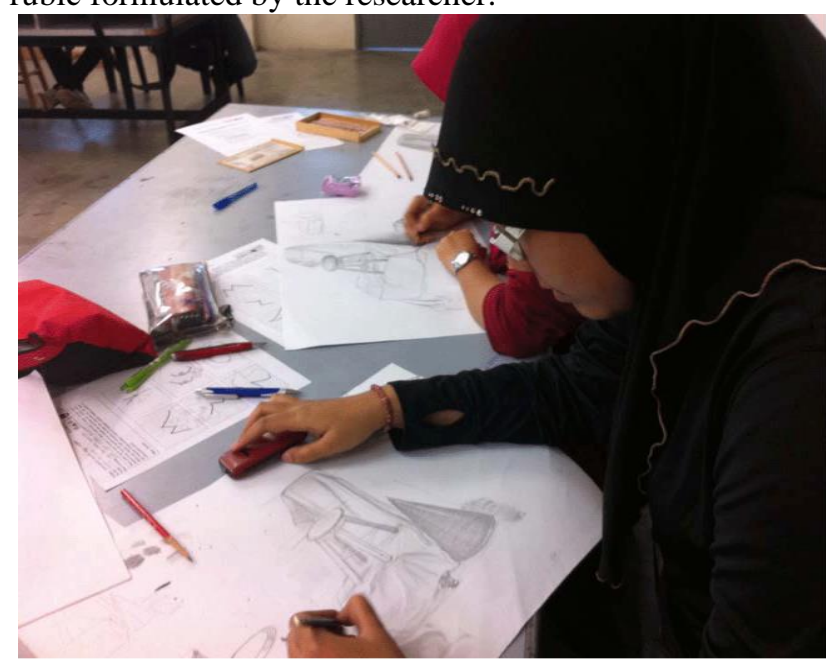

Fig. 2. Drawing test held after the student's university admittance

Once the students have completed their drawing, the research is continued by evaluation via the 5-dimensional rubric that has been produced. The evaluation was done according to the level of formalistic aspects used in the drawings produced by the students.

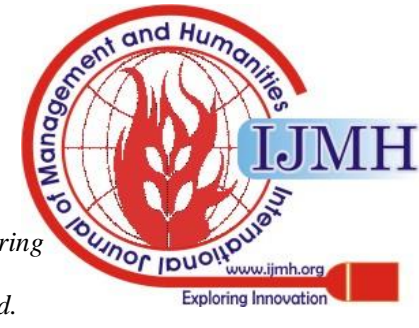


All drawings obtained from the respondents were analyzed by researchers specializing in the art of drawing and design. However, in order to ascertain the perfectness and translation soundness of drawing result analysis, the researcher have recruited four senior lecturers to help review and make amendments (if any).

This process is done to ensure that the data obtained from this drawing is accurate, did not show an inclination or biased (biased) and ensures its high reliability and accountability.

\section{B. Research Sample}

Presented here are several research samples of student drawings organized according to formalistic aspects.
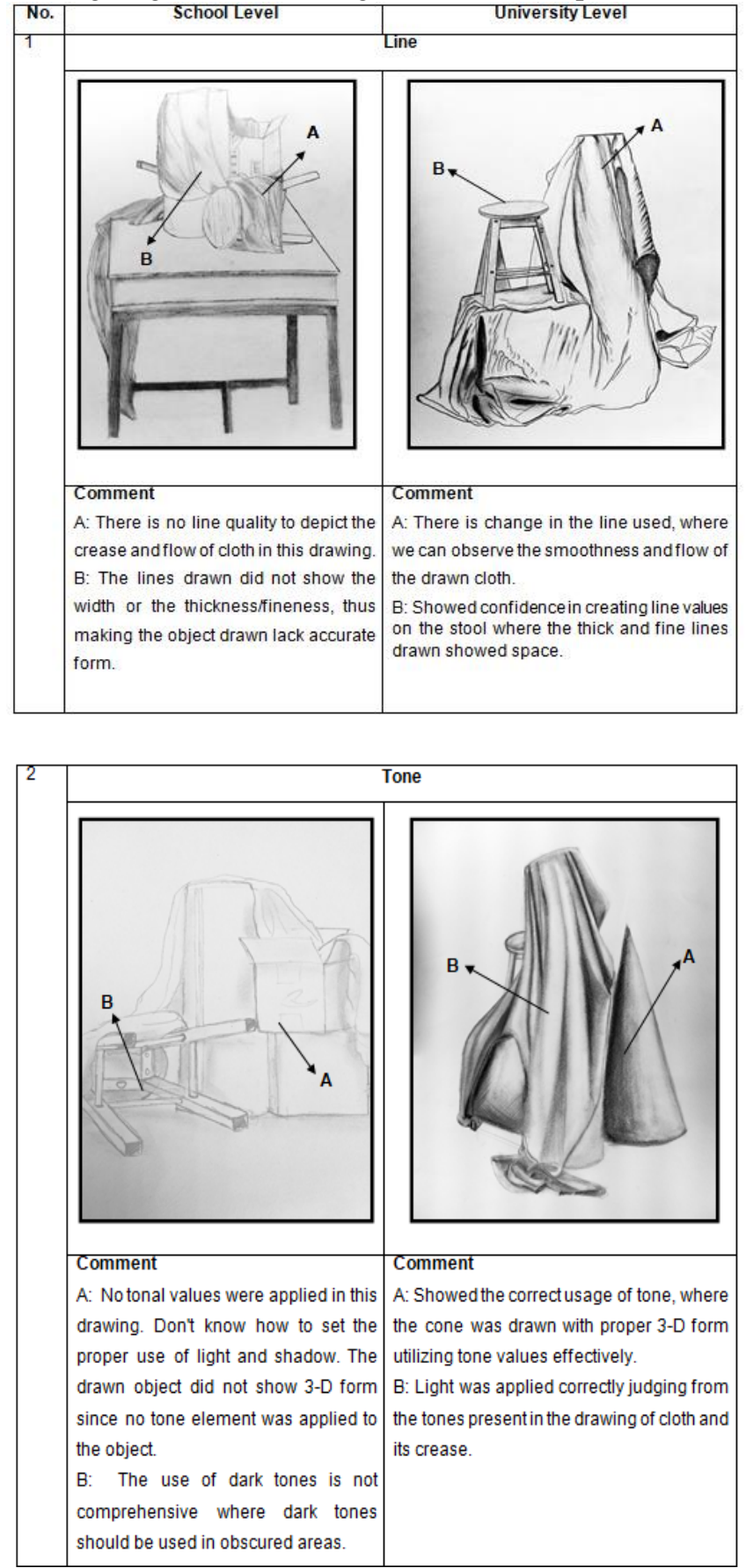

Published By:

Blue Eyes Intelligence Engineering

\& Sciences Publication

(c) Copyright: All rights reserved.
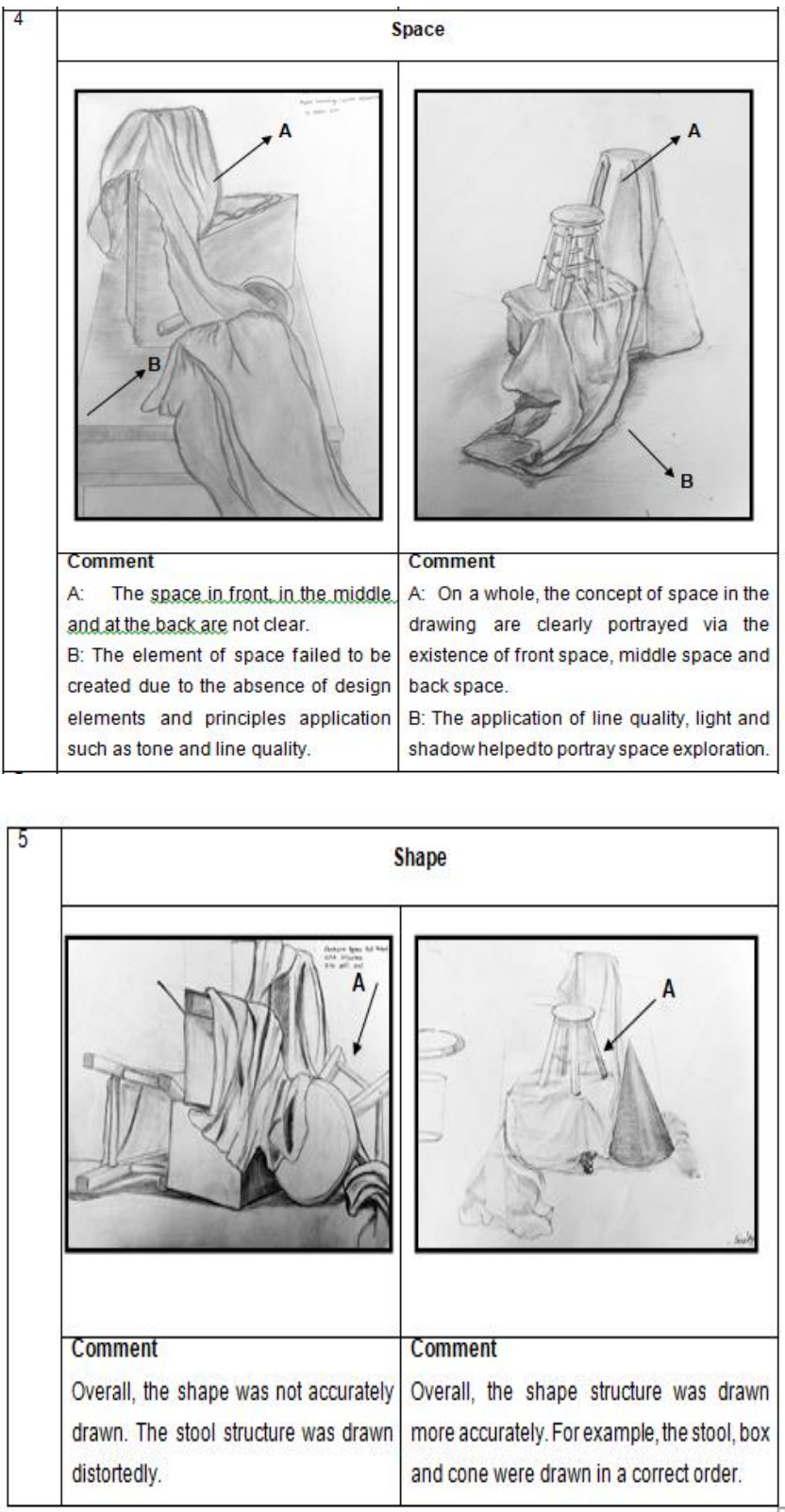


\section{RESEARCH ANALYSIS}

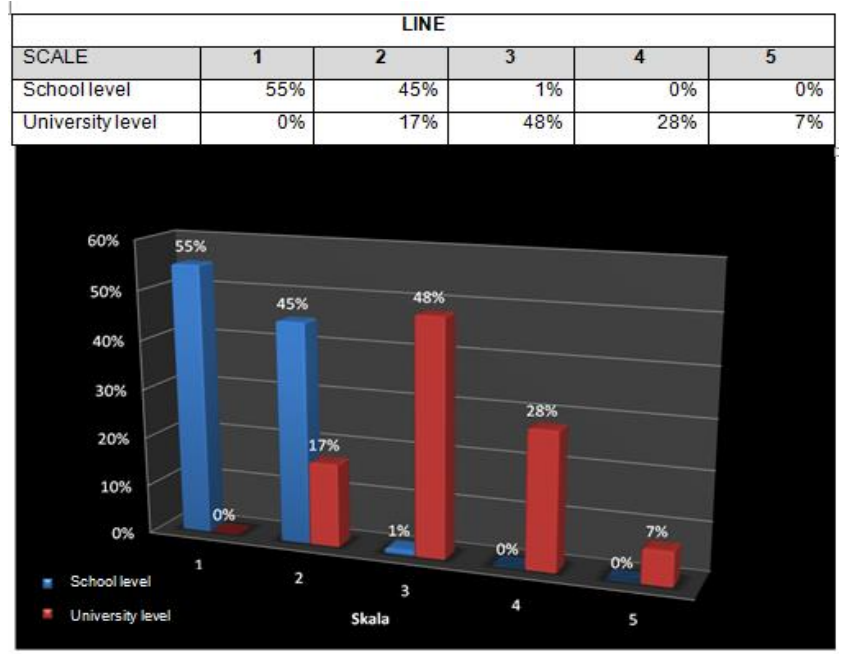

Chart 1. The creation of line value by school level students versus university level students

Scale Indicator:

1: Very weak and no line values

2: Drawing is sub-par, exhibit little comprehension in line usage

3: Line were used with the correct technique

4: Effective line usage in drawing

5: Quality line usage and showed high comprehension of quality and various contours aspects

The charts above showed the distinct difference in creating line values in the drawing by students. In scale 1, 55\% students are very weak and showed no line value use prior to entering the university. After university admittance, the scale 1 value is $0 \%$. This showed that all students managed to clearly grasp the line value needed in a drawing. This is the same for scale 3 , where after university admittance the percentage showed an increase to $48 \%$ (the use of line with correct technique) compared to the $1 \%$ showed prior university. On scale 5 (the use of quality line and showing high comprehension of quality and various contours aspects), students showed an increase of $7 \%$, compared to $0 \%$ prior university.

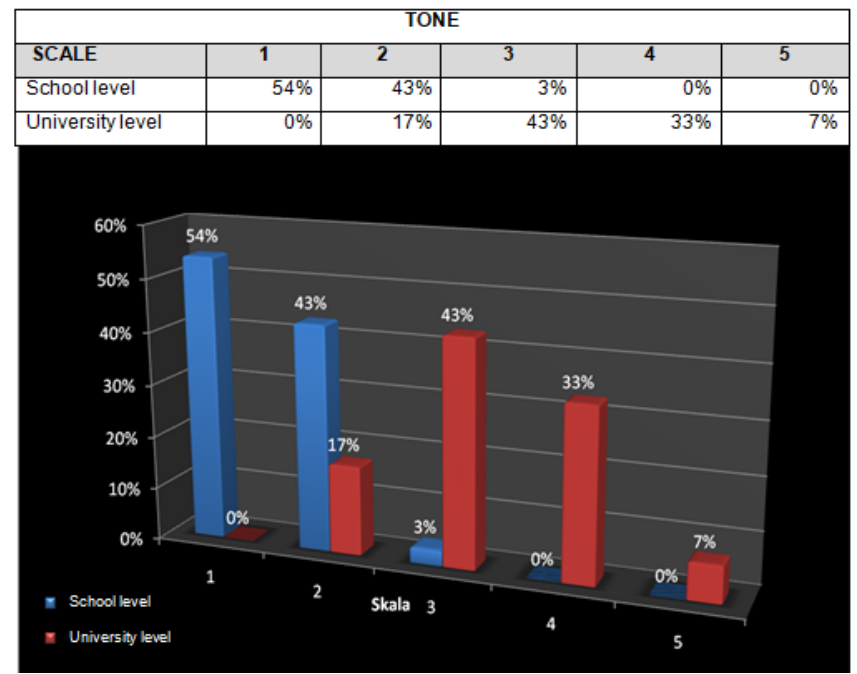

Chart 2. The creation of tone value by school level students versus university level students

Scale Indicator:
1: No comprehension and very weak

2: Created without any real comprehension of tone value

3: Tried to apply tone value but are still lacking in tone since the tone was drawn flatly.

4: The students used tone value effectively

5: Students completely comprehend tone value and applied all techniques in drawing.

Chart 2 showed that the most outstanding improvement was by scale 1 . Prior to university admittance, the students showed no comprehension and were very weak in tone value aspect. Almost half of the students involved in the drawing test performed weakly, which was shown by scale 1 at $54 \%$. They showed a reversal after university admittance and learned about formalistic aspects. This is proven in the chart above where every student showed tone value concept comprehension. A total of $43 \%$ students placed in scale 3 , that is tried to apply tone value but are still lacking in tone comprehension since the tone was drawn flatly. Compared to prior UiTM admittance which was given by $3 \%$, it was found that $7 \%$ of the total number of students enrolled into the university placed in scale 5 , that is complete comprehension of tone value and applied all techniques in drawing.

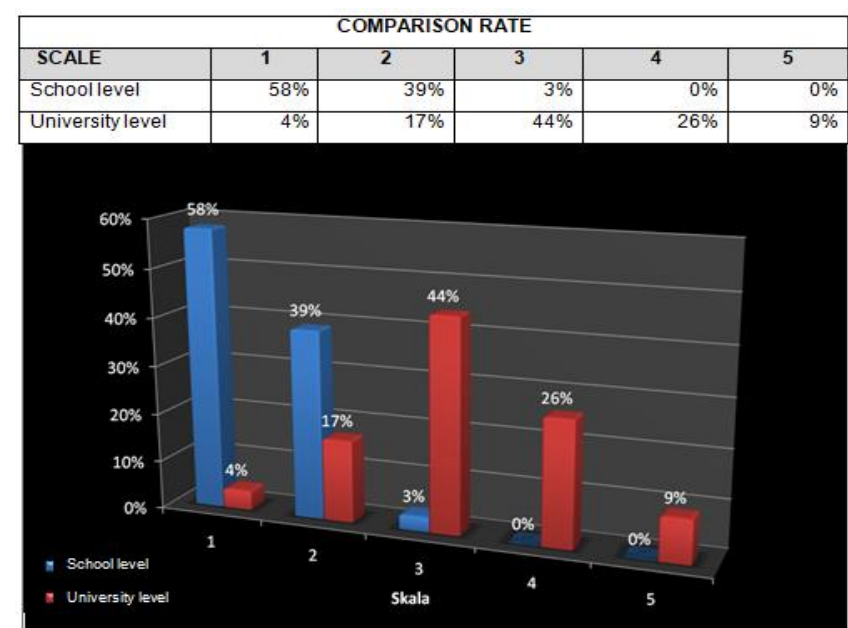

Chart 3. The creation of comparison rate element by school level students versus university level students

Scale Indicator:

1. No comprehension and no comparison rate in drawing

2. Weak and failed comparison rate usage

3. Little comprehension in comparison rate but unconvincing

4. Good use of comparison rate and is convincing

5. Students fully comprehend comparison rate value and successfully created perfect drawings.

Chart 3 clearly showed an increase in comparison rate among students in their drawings. The graph showed $4 \%$ at scale 1 where there is still lack of comprehension and no comparison rate in drawing, whereas $17 \%$ is placed at scale 2, that is weak comparison rate usage. For scale 3 , there was a distinct increase of $3 \%$ to $44 \%$.

This showed that the students are starting to comprehend and apply comparison rate albeit remaining unconvincing.

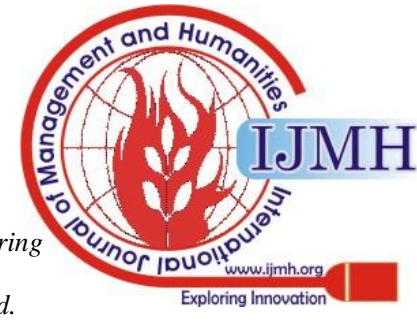




\begin{tabular}{|c|c|c|c|c|c|}
\hline \multicolumn{6}{|c|}{ SPACE } \\
\hline SCALE & 1 & 2 & 3 & 4 & 5 \\
\hline Schoollevel & $55 \%$ & $40 \%$ & $5 \%$ & $0 \%$ & $0 \%$ \\
\hline University level & $1 \%$ & $21 \%$ & $40 \%$ & $32 \%$ & $6 \%$ \\
\hline
\end{tabular}

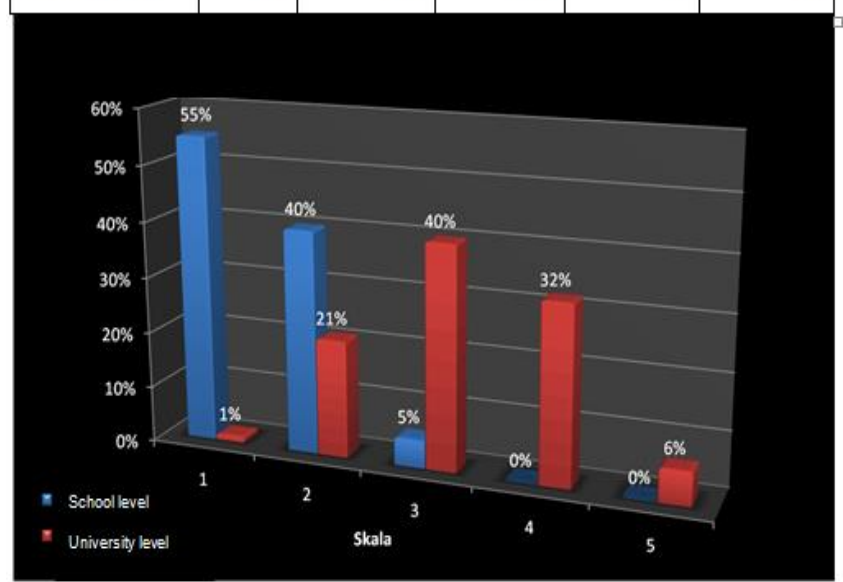

Chart 4. The creation of space element by school level students versus university level students

Scale Indicator:

1: No comprehension in creating space.

2: Only use a little comprehension when creating space.

3: Students showed space comprehension but is still yet to achieve the desired level.

4: The usage of interesting composition.

5: Good and precise use of space balance.

Assessment for space value showed that students failed to get through scales 4 and 5 , which are the scales for being able to present drawings that fulfilled the design aspects of elements and principals where they scored $0 \%$. However, as we can see from the space graph, a total of 55\% students did not comprehend space creation at all while scale 2 showed $40 \%$ students have comprehension. For scale 3, students showed space comprehension but only at $5 \%$.

The result for space application can be seen in the graph, where we can observe a distinct progress. For scale 1, there is a $54 \%$ decrease to $1 \%$ for no comprehension in creating space, followed by scale 2 with a $19 \%$ decrease, that is from $40 \%$ to $21 \%$. Scale 3 showed a good increase from $5 \%$ to $40 \%$ for students showed space comprehension but is still yet to achieve the desired level.

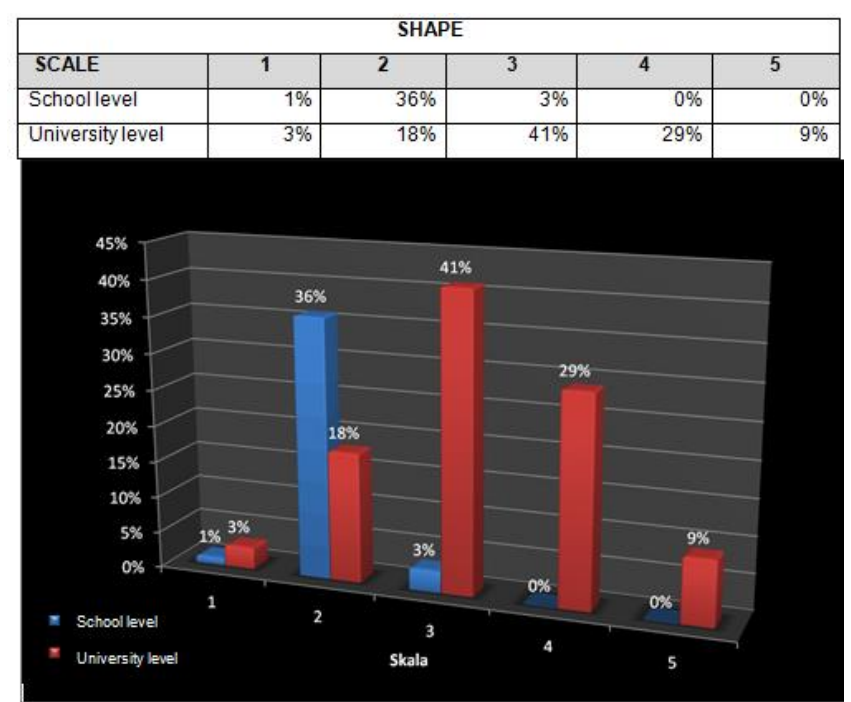

Chart 5. The creation of shape element by school level students versus university level students

\section{Scale Indicator:}

1: No comprehension in creating shape

2: Used only a little structure in shape creation

3: A little comprehension in structure usage but is still unconvincing.

4: Use good and convincing shape.

5: Students comprehend shape and successfully created perfect drawing.

Graph evaluation showed only $1 \%$ placed at scale 1 while $36 \%$ and $3 \%$ placed at scale 2 with $3 \%$ for scale 3 , where no one exceeded the levels of scale 4 and scale 5 .

\section{RESEARCH FINDINGS}

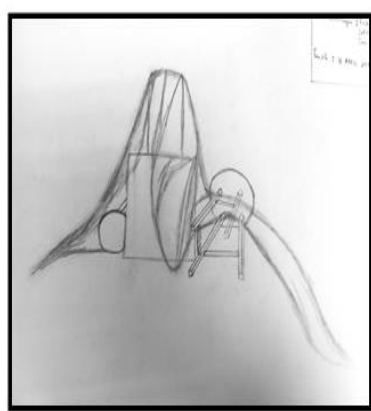

Schoollevel

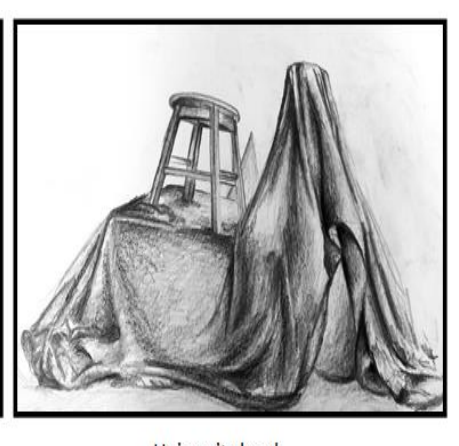

University level
Fig. 3. The application of formalistic aspects at school level versus university level

The results of the study can be summarized by referring to the review of the five graphs showing the presence of a corresponding increase, i.e. the measurement of the increase from scale 1 and beyond scale 3 .

1) Line

The line element analysis chart at scale 1 (school level) gave $55 \%$, and an increase occurred at scale 3 at $48 \%$.

2) Tone

Scale 1 (school level) for tone element showed 54\%, while scale 3 showed an increase at $43 \%$.

3) Comparison Rate

Comparison rate element at scale 1 (school level) showed $58 \%$ while increases to $44 \%$ at scale 3 .

4) Space

An increase for space element for $40 \%$ at scale 3 compared to $55 \%$ at scale 1 (school level).

\section{a) Similarity}

The results of this research show that the almost equal level of improvement in all four of the above formalistic aspects $(1,2,3,4)$ is likely to be due to:

1) The similar range of SPM candidates age which is approximately 17-18 years

2) The same university enrollment requirement which is SPM leavers; and

3) All candidates are citizens of Bumiputera descent.

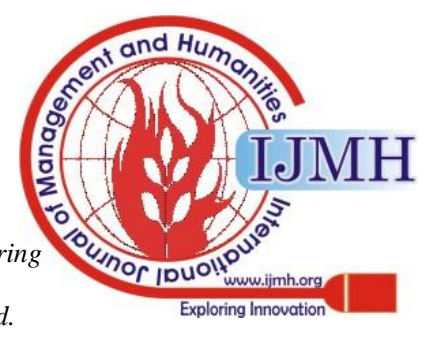




\section{b) Difference}

The findings show a significant value at scale 1 for formalistic aspect 1 , the line element. School level drawing assessment showed 55\% students are weak with no line elements application.

However, the chart showed $0 \%$ after university enrollment, which is there is no weak student and line element use showed an increase.

Referring to Fig. 3, the difference between line usage is the most striking. The students are more encouraged and focused in creating quality line.

This clearly showed that the students completely grasp the use of various pencils for different line types of the object drawn.

The results of interviews with 5 Visual Arts Education teachers in Kelantan have shown that students have not been exposed to the correct use of line quality. For example, students produce drawing by drawing lines that were then rubbed using the rubbing technique to get the shapes they wanted.

The Visual Teaching and Education System of schools did not focus solely on drawing. In fact, it is predisposed towards the creation of artworks such as batik, printing, graphic and the likes. This in turn enables the student to lose total focus in creating high quality drawing.

\section{SUGGESTIONS}

Here are some suggestions for improvement based on the findings above:

1) Drawing is a core subject in Visual Arts Education and needs to be more emphasized in comparison to other artworks. Therefore, in the creation of a drawing, quality line use is of crucial focus in order to produce high quality drawing.

2) In the art of drawing, students should also have ample and accurate references to supplement their knowledge and understanding of producing good drawings at the school level using a variety of reference books that is not limited to school textbooks exclusively. Teachers can take the initiative by providing them exposure outside of the classroom, for example visiting art galleries, art schools and higher learning institutions that offer art education.

\section{CONCLUSION}

This work has successfully identified the use of formalistic aspects in the school curriculum and the Art and Design curriculum during drawing creation, namely the line elements, tone values, comparison rate, space and shape structure. Research findings showed that line element, tone, comparison rate and space exhibited distinct increase while not much so for shape structure.

In conclusion, the researchers believe that the suggestions mentioned above can be taken into consideration by all the parties involved, especially the secondary schools of the Ministry of Education. All suggestion presented were outputs to results obtained from the research.

It is hoped that this research will help the Ministry of Education to resolve any shortcomings in their teaching and learning system. In addition, we would also suggest that Visual Arts Training to be revamped, modified or perhaps restructured in such a way that it is appropriate and up to date.

\section{REFERENCES}

1. Ching, F.D.K and Juroszek, SP (2010). Design Drawing (2nd Edition). John Wiley \& Sons.Inc.Hoboken. New Jersey

2. Michael, J.A.,(1982). The Lowenfeld Lectures. University Park, PA: Pennsylvania State University Press.

3. Pipes,A (2008). Foundations of Art \& Design (2nd Edition). Laurence King Publishing Ltd. London.

\section{AUTHORS PROFILE}

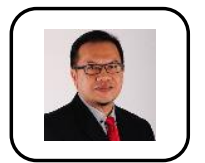

Marzuki Ibrahim is a professor in the School of Industrial Design at the Faculty of Innovative Design and Technology, Universiti Sultan Zainal Abidin Malaysia. He is one of the fellows on the RSA United Kingdom and assessors on the MQA since 2000. He is also one of the professional technologists (Ts.) on the MBOT. He holds a Diploma in Industrial Design from UiTM Malaysia and BA/MA in Industrial Design Eng. from Leicester Univ. UK. Upon returning to his homeland, he began to work as a senior lecturer at UiTM Malaysia for a few years later before flewing back to UK to pursue his MPhil/h.D. in Design Mgmt. in Newcastle Univ. During his tenure with UiTM Malaysia, he has contributed a lot of energy through the consultation of design projects with Pusat Daya Cipta UiTM. In the academic field, his writings have appeared in many exhibition catalogs, journals, magazines and newspapers. He had delivered numerous research papers nationally and internationally and has invited as an academic reviewer, speaker, moderator, external examiner and guest lecturer. He is also a supervisor-cum-advisor for Master and Ph.D. students in Art \& Design fields.

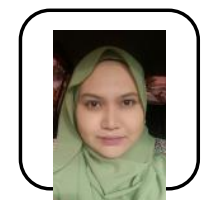

Hartini Mohd Razali is a senior lecturer in the Department of Visual Cultural Studies at the Faculty of Art and Design UiTM Kelantan. She began her Diploma studies in UiTM Kelantan in textile design and pursued a Degree in the same field at UiTM Shah Alam. She has huge interest in art history and has continued her Masters studies at UiTM Shah Alam in the field of Art History and Cultural Management. While studying, she was offered as a lecturer in the field of liberal/visual culture studies right after she graduated. During her service as a lecturer, she has come out with number of researches and presented them at national and international level. She is currently as a $\mathrm{PhD}$ student at Faculty of Innovative Design and Technology, University Sultan Zainal Abidin Terengganu. Besides that, she is also a supervisor of Bachelor students of Art \& Design at UiTM Kelantan.

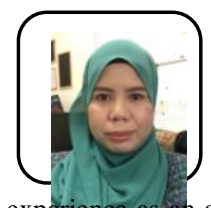

Mazni Omar is a lecturer in Visual Cultural Studies at the Faculty of Art and Design UiTM Kelantan. She obtained a Diploma in Art and Design (Fine Art) at UiTM Kelantan and furthered her studies to Degree level (Hons) in Fine Arts. After graduation she worked in several private companies as a designer and had experience as an assistant lecturer at the Faculty of Architecture, Planning and Survey UiTM Shah Alam. She then continued her Masters in Art History \& Cultural Management. In the academic field, she has conducted researches and presented the papers nationally and internationally. She is currently a supervisor for a group of Bachelor students in Art \& Design. Besides that, she also is a PhD student at Faculty of Innovative Design and Technology, University Sultan Zainal Abidin, Terengganu.

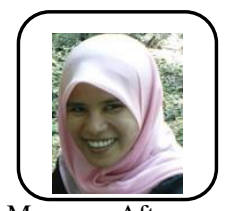

Siti Fairuz Md Hashim is a Senior Lecturer of Visual Cultural Studies at the Faculty of Art \& Design, UiTM Kelantan. She has started her Degree in Graphic Design at Uitm Melaka and pursuing BA (hons) in Graphic Design at Uitm Shah Alam. After graduation, she worked as an assistant curator at Kelantan State Museum. After a year she joined Cosmopoint College as a Graphic Lecturer before pursuing her MA in Visual Communication and New Media at UiTM Shah Alam. Upon pursuing MA, she began to work as a part time lecturer in UiTM Kelantan and after successfully completing her MA she was offered position as a permanent lecturer at UiTM Kelantan in the Visual Cultural Studies Department. In the academic field, she has presented research papers nationally and internationally. In present, she is a supervisor for a number of Bachelor students of Art \& Design. Besides that, she also is a PhD student in Faculty of Art \& Design at University Teknologi MARA, Shah Alam. 
Mohammed Iqbal Badaruddin (b.1985) is a lecturer in Department of Visual Culture Studies, Faculty of Art and Design, Universiti Teknologi MARA Kelantan, Machang Campus. Iqbal received his Master in Fine Art and Technology, Universiti Teknologi MARA in 2010. Other than Fine Art, Iqbal also interest to art history, art anthropology, islamic art and graphic designs. Upon his servicing at UiTM, Iqbal has been actively involved in art exhibition. His print artwork exhibited local and international specially for Kuala Lumpur Mini Print Exhibition 2018 (National Art Gallery Malaysia) and 2nd International Enter Into Art Exhibition 2016 (Culture Centre, Cologne, Muhlheim-Germany). Iqbal also active in academic writing and have published few articles for journals and art catalog and exhibitions. His interest in comic had pursued him to partneship with Ustaz Luqman in creating Kaifa Haluka®: Karikatiy Arabiyy as one of the method to learn arabic language with bahasa Malaysia translation. With QR Code output, the comic book can integrated with listening. Enable his team won the major award in invention and innovation design (IID) 2017 and 2018. Iqbal currently writing his thesis dissertation on the cultural polemics surrounding Bajau weaponry. 